\title{
CRESCIMENTO E RENDIMENTO DE CULTIVARES DE QUINOAEM REGIÃO SEMIÁRIDA UTILIZANDO DIFERENTES ADUBOS ORGÂNICOS.
}

Autores: Valéria Valesca da Silva Brito

Ana Paula Pereira dos Santos

Luany Gabriely da Silva

Renato Silva de Castro

\section{Introdução}

A quinoa (Chenopodium quinoa Willd.) é uma espécie granífera que foi domesticada pelos povos que habitavam a cordilheira dos Andes há milhares de anos. A quinoa foi introduzida no Brasil na década de 1990, para diversificar os métodos de produção do cerrado, e pode ser considerada uma excelente alternativa de produçao, naja a vista todas as partes da quinoa serem aproveitadas, desde o grão utilizado nas indústrias de alimentos e de rações até a planta inteira na alimentação animal (SPEHAR; SANTOS, 2002 apud SPEHAR 2007, p. 21). Este tipo de cultura pode atender a sistemas agrícolas mais sustentáveis com enfoque agroecológico, muito utilizado pela agricultura familiar nordestina (KÜSTER, 2004), servindo como opção de rotação de cultura, aproveitando a adubação residual destas áreas e também utilizando a sua massa vegetal para cobertura do solo, promovendo alimentação humana de alta qualidade nutricional.

\section{Fundamentação Teórica}

Conforme Spehar; Santos (2002), diz que a Quinoa, pertencente à família Amaranthaceae, subfamília Chenopodioideae, é uma espécie granífera, domesticada pelos povos habitantes da Cordilheira dos Andes há milhares de anos. "A quinoa é uma halófita, ou seja, é uma planta com habilidade de suportar não apenas altos níveis de salinidade do complexo solo-água, mas, também, de acumular significativas quantidades de sais em seus tecidos" (ORSINI, F.; ACCORSI, M.; GIANQUINTO, G., 2011; YUDA H; KARL, M.; YU, T.; et al. 2011). "O adubo ou fertilizante orgânico é o produto de origem vegetal, animal ou agroindustrial que aplicado ao solo proporciona a melhoria de sua fertilidade e contribui para o aumento da produtividade e qualidade das . culturas" (TRANI, et. al, 2016, p. 1).

\section{Metodologia}

A parte experimental será desenvolvida no Instituto Federal de Educação, Ciência e Tecnologia do Rio Grande do Norte (IFRN) Ipanguaçu, e será conduzida em casa de vegetação.

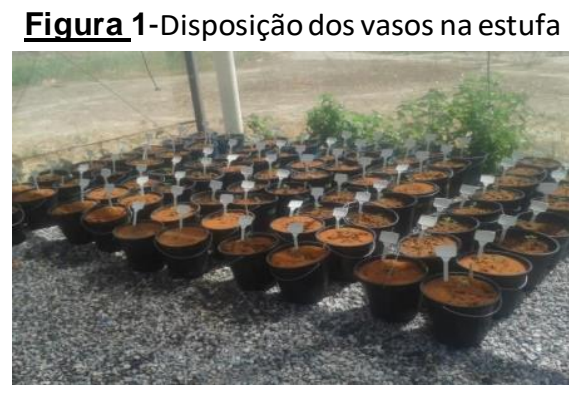

Fonte: Elaborado pelo autor (2016) Figura 3-Peso fresco da parte aérea.

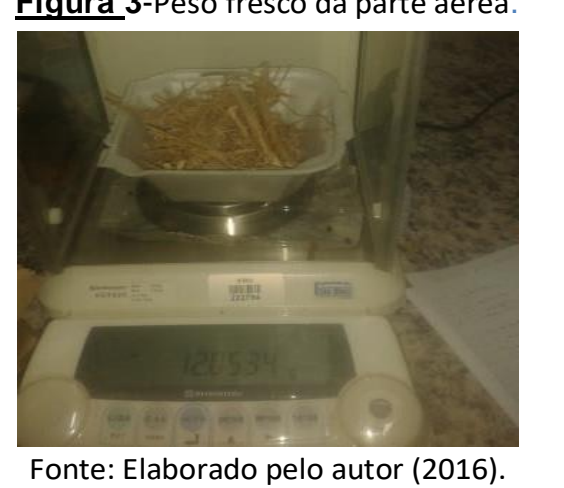

\section{Resultados e Discussão}

Os dados da altura das plantas foram transformados para $x$ de forma que obtivessem uma distribuição normal. A análise de variância demostrou que ocorreu interação entre os fatores Cultivar (F1) e Adubação (F2) utilizados, ou seja, este resultado implica que os efeitos dos fatores atuam de forma dependente. As comparações entre os níveis de um fator levam em consideração o nível do outro fator, pois o resultado significativo para a interação indica que o efeito de um fator depende do nível do outro fator (Figura 18).

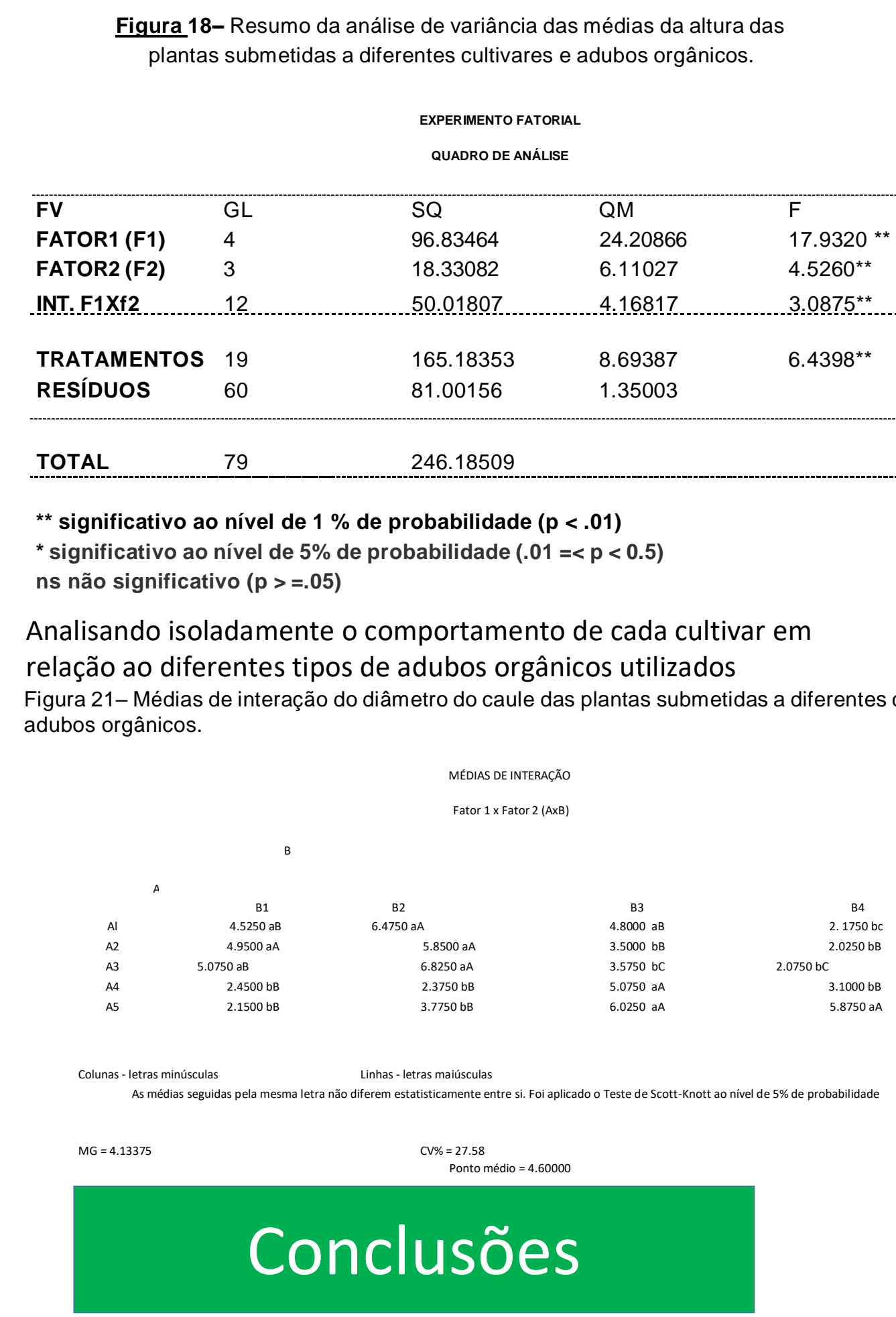

-As características avaliadas tiveram respostas diferenciadas conforme o tipo de cultivar e adubos utilizados.

-Com relação aos adubos, os estercos Ovino e Bovino atenderam a todas as cultivares, já o Húmus proporcionou maiores produções somente para Kancolla, BRS Syetetuba e Oruro preta.

- Nas condições do experimento, as características avaliadas, evidenciam o seu potencial para a região, principalmente no aspecto mais relevante para o produtor, a produtividade obtida, incentivando novas pesquisas em condições de campo.

\section{Referências}

SPEHAR, C. R. Quinoa: alternativa para a diversificação agrícola e alimentar. Planaltina: Embrapa Cerrados. 1. ed. Planaltina: editor técnico Carlos Roberto Spehar, 2007. 103 p.

KÜSTER, Angela. Agricultura familiar, agroecologia e mercado no Norte e Nordeste do Brasil. Fundação Konrad Adenauer 2004

ORSINI, F.; ACCORSI, M.; GIANQUINTO, G. Beyond the ionic and osmotic response to salinity in Chenopodium quinoa: functional elements of successful halophytism. Functional Plant Biology, v. 38, n. 10, p. 818-831, 2011.

TRANI, P. E.; TERRA, M. M.; TECCHIO, M. A.; TEIXEIRA, L. A. J.; HANASIRO, J. Adubação Orgânica de Hortaliças e Frutíferas. $<$ http://www.iac.sp.gov.br/imagem informacoestecnologicas/83 .pdf $>$. Acesso em 26 ago. 2016. 